\title{
Adverse events following immunization against COVID-19 among healthcare workers: An observational study in Haryana, India
}

\author{
Chintu Chaudhary', Mukhmohit Singh², Mohd. Najmul Aqib Khan ${ }^{3}$, Bhupinder Kaur Anand ${ }^{4}$ \\ Shveta Saini ${ }^{5}$ \\ ${ }^{1}$ Asscociate Professor, ${ }^{4}$ Professor, Department of Community Medicine, Al-Falah School of Medical Sciences and \\ Research Centre, Dhauj, Haryana, ${ }^{2}$ Principal Faculty, ${ }^{5}$ Admin Faculty, Department of Community Medicine, National \\ Institute of Medical Education, Kayamkulam, Kerala, ${ }^{3}$ Assisstant Professor, Department of Community Medicine \\ Government Medical College, Haldwani, Uttarakhand, India
}

Background: COVID-19 is a novel coronavirus leading to rampant spread and pandemic ongoing since March 2020. Scientists/researchers and professionals from health-care related disciplines started tremendous efforts for early rollout of the vaccine and vaccines started coming out by the end of the year 2020. India rolled out two vaccines developed in India itself on January 6 and started the world biggest vaccination drive for nearly 2 lakh frontline healthcare and sanitary workers, on January 16, 2021. Because COVID-19 vaccines are novel vaccines, information on risk of rare serious vaccine reactions are limited. Aims and Objectives: The aim of the study was to assess the adverse drug reactions following immunization with Covishield Vaccine. Materials and Methods: The present study is an observational follow-up study to asses any adverse events following immunization (AEFI) occurrence within 7 days of vaccination among all eligible participants who were vaccinated under the field practice area of Rural Health Training Center, Al-Falah School of Medical Sciences and Research Center, Faridabad (Haryana). Results: The overall incidence of any AEFI within 7 days was found to be $136 / 1000$ vaccinations for the first dose. Out of total 97 recipients reported with adverse events, $76.3 \%$ had AEFI within $24 \mathrm{~h}$ with fever as the most common symptom reported. The incidence of AEFI's was found to be associated with gender $(P<0.02)$ and age group $(P<0.05)$ and occupation $(P<0.05)$. Conclusion: Most of the adverse events were short-lived and observed in the first 24 hours of vaccination. Incidence decreased in subsequent days and no serious AEFI was reported.

Key words: Adverse events following immunization; Covishield vaccine; Healthcare workers; Immunization

\section{INTRODUCTION}

In India, first case of COVID-19 was reported in January 2020 but the actual number started rising only in March 2020 and kept on increasing for the rest of the year. ${ }^{1}$ Scientists all over world started working for the vaccine development against COVID-19 in mid-2020 and vaccines started coming out by end of the same year, specially in UK. ${ }^{2}$ India rolled out two vaccines, developed in India itself, on January 6 and started world's biggest vaccination drive for nearly 2 lakh frontline, healthcare and sanitary workers, on January 16, 2021.3

Adverse event following immunization (AEFI) is any untoward medical occurrence which follows immunization, and which does not necessarily have a causal relationship with the usage of the vaccine. ${ }^{4}$ Vaccine-associated adverse events may affect healthy individuals and should be promptly identified to allow additional research and appropriate action to take place. If not rapidly and

Address for Correspondence:

Chintu Chaudhary, Associate Professor, Department of Community Medicine, Al-Falah School of Medical Sciences and Research Centre,

Dhauj, Haryana, India. Mobile: +91-9643099272. E-mail: chaudharychintu@gmail.com 
effectively dealt with, these events undermines people's confidence in a vaccine and can ultimately lead to dramatic consequences for immunization coverage and disease incidence. ${ }^{4}$ As we know, every new treatment or prevention requires experiments and trials, and carries risks, thus in absence of any previous experience with vaccines against COVID-19, the possibility of AEFI cannot be ruled out.

The WHO established a Global Advisory Committee on Vaccine Safety to respond promptly, efficiently, and with scientific rigor to vaccine safety issues. ${ }^{4}$ Latest vaccines to consider for the adverse effects are the ones developed to counter the ongoing COVID-19 pandemic. A number of pharmaceutical companies, worked extremely hard to roll-out with an potential vaccine against COVID-19 including Inactivated or weakened virus vaccines, Proteinbased vaccines, Viral vector vaccines, and RNA and DNA vaccines, all of which shown to have different efficacy and adverse effects. ${ }^{5}$ Reported adverse effects include: normal vaccination reactions such as redness, swelling, or pain around the injection site along with fatigue, fever, headache and aching limbs, and also some rare serious side effects such as allergic shocks. ${ }^{6}$ Since vaccination drive started in the country, concerns about adverse effects, as of now, seems to be pacified as initial data from different parts of the country, ${ }^{7}$ signifies their low incidence, and rare seriousness. ${ }^{8-10}$ Similar scenario was also reported from other countries as well..$^{11,12}$

Because COVID-19 vaccines are novel vaccines, information on risk of rare serious vaccine reactions would have been limited at the time of their regulatory assessment and registration. Hence, the present study will help to assess the adverse drug reactions following immunization with COVID vaccine. This study was done on the entire population of health workers under the Community Health Center, which is also the Rural Health Training Center (RHTC) of Al-Falah School of Medical Sciences and Research Center (AFSMS and RC) at Kheri Kalan, which has a large catchment area in Greater Faridabad (state of Haryana). This is also a designated vaccination center for COVID-19 besides serving as COVID care center. This is new area of research given that the disease and its vaccine are new. We could not find any published study from India, during the write-up of this study, where this theme was explored. Hence, the study will help identify and document adverse events associated with COVID-19 vaccination. The study will help decision makers in making more informed decisions to take care of the unfortunate outcomes among the vaccine recipients.

\section{Aims and objectives}

The aim of the study was to document the adverse effects of COVID-19 in terms of their frequency, severity, and related determinants, among healthcare workers, received the newly approved COVID-19 vaccine.

\section{MATERIALS AND METHODS}

This is an observational, follow-up study, which was conducted among all the beneficiaries of COVID-19 vaccine at vaccination centers under the field practice area of RHTC, AFSMS, and RC, Faridabad (Haryana) after taking ethical clearance from the concerned committee (AFSMS and RC/F-124/21/72). The participants were selected for the study based on the following inclusion and exclusion criteria:

\section{Inclusion criteria}

All the beneficiaries, received COVID-19 vaccine in the first phase in the field practice area of RHTC, Kheri Kalan, AFSMS and RC, and were willing to participate in the study.

\section{Exclusion criteria}

Individuals, who did not give consent, had history of allergic response to any vaccine, with immune compromised state or on immunosuppressant drugs, pregnant and lactating females, and those who could not be contacted telephonically for follow-up, after three attempts.

\section{Study tools}

Questionnaire, Infra-red thermometer, and Pulse oximeter.

The study was planned and carried out after approval by AFSMS and RC Ethics Committee. Approval was also taken from the district health authorities for permission and cooperation to conduct this study. The study sample size was open, and all eligible subjects were selected. Complete enumeration of the selected subjects was done, and a study ID was assigned to each vaccine recipient during the first session of vaccination series (discussed below in the results section). Later all the subjects who attended the second vaccination series were matched using photo ID, date of birth, gender, mobile number, and name to assess the second vaccination turn out rate at respective centers.

The data of the eligible study participants were collected in a pre-tested and printed questionnaire either at first contact or on the day of vaccination. The first response was recorded in person, at the vaccination center after half an hour, then telephonically after $24 \mathrm{~h}$ and then again after 1 week of vaccination. The subsequent telephonic follow ups were done in-depth using a pre-tested questionnaire by trained Nurse/Trained Health worker from Community Health Centre (CHC) (RHTC- AFSMS and RC) Kheri Kalan, Faridabad under the supervision of investigators.

The data were collected, compiled, and statistically analyzed using MS Office Excel and SPSS ver21. The continuous variables were analyzed using mean and standard deviation, while the categorical variables were assessed using frequency and percentages. The test for significance was done using 
Chi-square test with appropriate degree of freedom and at 95\% confidence limits and at $\mathrm{P}<0.05$ significance level.

\section{RESULTS}

The study was conducted over two series of COVID vaccination drive sessions. The vaccine used for COVID vaccination was Covishield vaccine produced by AstraZeneca Pharmaceuticals, is a Recombinant Covid-19 vaccine based on Viral Vector technology.

The data were obtained from a total of 714 subjects, who were enrolled for the first dose of Covishield vaccine during the vaccination drive, at six centers under the field practice area of AFSMS and RC, from January 16 to February 8, and later 611 participants were enrolled for vaccination during the second lap of vaccination drive from February 13 to March 5, 2021. Overall, 86\% of the total $1^{\text {st }}$ time enrolment received their second dose at respective vaccination centers.

In this study, the enrolled females $(\mathrm{n}=427,59.8 \%)$ were higher than males $(n=287,48.2 \%)$. The mean age was found to be $32.69 \pm 11.6$ years, and most of the participants were 18-39 years of age $(72.0 \%)$. The respondents were also categorized based on the occupational categories and Multipurpose workers, Accredited Social Health Activist (ASHA), Anganwadi workers, and other field staff were the major field level workforce (45.4\%) (Table 1).

In the study, 68 individuals $(9.5 \%)$ reported to have documented comorbidity, out of which 61 individuals $(90 \%$ of participants with comorbidity) had either hypertension or diabetes or both (Figure 1).

Adverse events following Immunization (AEFI) were assessed and followed up in regular intervals with first reporting of AEFI within 30 min, then within 1 day $(24 \mathrm{~h})$ and then any AEFI within 7 days. The overall incidence of any AEFI reported (including any major, minor or coincidental events) with the first dose vaccination, and was found to be $136 / 1000$ vaccination events ( $n=97)$, with most people experiencing any AEFI after 30 min but within $24 \mathrm{~h}$ following immunization ( $\mathrm{n}=74)$ (Figure 2$)$. After the subsequent second dose of vaccination, only two persons (3/1000 vaccinations) experienced mild symptoms and remaining 609 did not experience any symptoms after the vaccination. The results shown in this study are from the first dose of COVID vaccination.

The spectrum of symptoms reported within $30 \mathrm{~min}$ of vaccination ranged from local events (redness and itching) to systemic or generalized symptoms such as Ghabrahat,

\begin{tabular}{|c|c|c|c|}
\hline Variable & $\begin{array}{c}\text { Female } \\
\text { n (\%) }\end{array}$ & $\begin{array}{l}\text { Male } \\
\mathrm{n}(\%)\end{array}$ & $\begin{array}{l}\text { Total } \\
\text { n (\%) }\end{array}$ \\
\hline \multicolumn{4}{|l|}{ Age groups } \\
\hline $18-39$ years & $312(43.7)$ & $202(28.3)$ & 514 (72.0) \\
\hline $40-59$ years & $109(15.3)$ & $78(10.9)$ & $187(26.2)$ \\
\hline $\begin{array}{l}\text { More than } 60 \text { years } \\
\text { Occupation Categories }\end{array}$ & $6(0.8)$ & $7(1.0)$ & $13(1.8)$ \\
\hline $\begin{array}{l}\text { Housekeeping - } \\
\text { Drivers, Sanitary } \\
\text { workers \& other } \\
\text { Class IV emblovees }\end{array}$ & $29(4.1)$ & $76(10.6)$ & 105 (14.7) \\
\hline $\begin{array}{l}\text { HCW'S - MPWs, } \\
\text { ASHA, AWW, AWH, } \\
\text { Field workers }\end{array}$ & $240(33.6)$ & $84(11.8)$ & $324(45.4)$ \\
\hline $\begin{array}{l}\text { Paramedical - } \\
\text { Nurses }\end{array}$ & $26(3.6)$ & $24(3.4)$ & $50(7.0)$ \\
\hline $\begin{array}{l}\text { Medical staff. - } \\
\text { Medical officers, } \\
\text { doctors }\end{array}$ & $38(5.3)$ & $31(4.4)$ & $69(9.7)$ \\
\hline $\begin{array}{l}\text { Office staff - } \\
\text { Administrative, } \\
\text { clerical staff }\end{array}$ & $24(3.3)$ & $37(5.2)$ & $61(8.5)$ \\
\hline Others - Students & $70(9.8)$ & $35(4.9)$ & 105 (14.7) \\
\hline
\end{tabular}

*HCW's: Healthcare workers, ASHA: Accredited Social Health Activist, MPWs: Multipurpose workers, AWW: Anganwadi workers, AWH: Anganwadi helpers

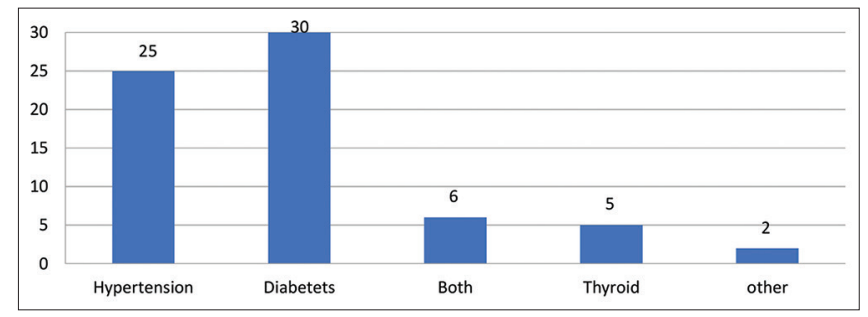

Figure 1: Comorbidity profile of vaccine recipients $(n=68)$

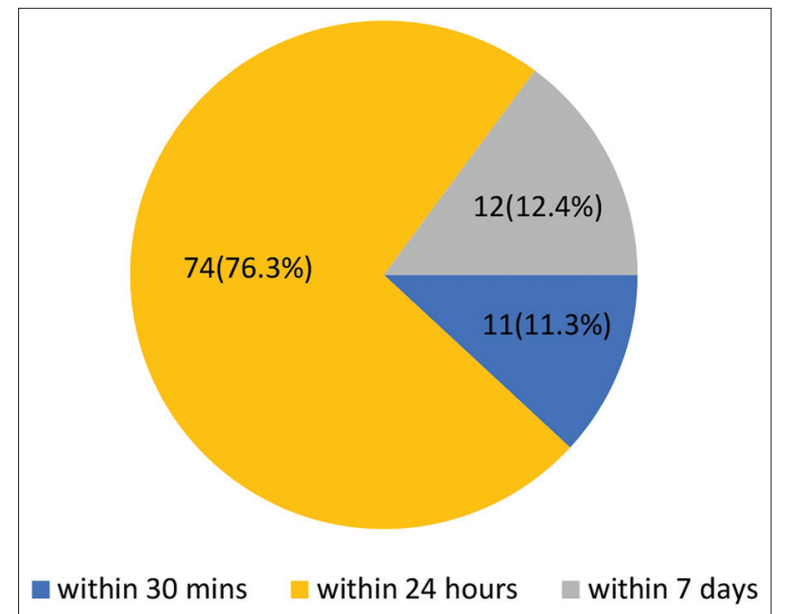

Figure 2: Distribution of beneficiaries with time of onset of adverse event

or tachycardia were most common $(n=6)$. A total of 75 AEFIs were reported within $24 \mathrm{~h}$ with the most common complaint being onset of fever within $24 \mathrm{~h}(\mathrm{n}=59,58.4 \%$ among any AEFI reported). The occurrence of AEFI 
within 7 days of vaccination was reported to be 15 , where the most frequent symptom was fever $(11.9 \%$ of all AEFI reported) (Table 2).

The incidence of any AEFI did not have any statistically significant association with gender, age groups, or presence of any comorbidity. However, the occurrence of any AEFI had a statically significant association with the occupation categories with Category I and Category IV staff having the highest incidence of AEFI reporting (Table 3).

On further analysis, the AEFI within 30 min was found to have statistically significant association and was observed to be higher in females but did not show a statically significant association with comorbidity and age groups (Table 4).

AEFIs reported within 24 hours was observed to have a statistically significant association with the age, with $16 \%$ of all individuals age group 40-59 years reported some AEFI within 24 hours. (table 4). The AEFI within 7 days did not show a statistically significant association with age group, or comorbidity or gender (Table 4). The AEFIs within 24 hours also found to have statistically significant association with the occupation ( $\mathrm{p}=0.005$ ), with $23 \%$ of housekeeping staff including drivers, support workers, class IV employees, reported to have experienced AEFI within 24 hours (Figure 3). However, it was observed that highest number of AEFI within 7 days were reported by housekeeping staff followed by and medical personnel (Figure 3).

\section{DISCUSSION}

Adverse events reported in the present study, after the administration of Covishield vaccine, were non-serious in majority. Overall 97 (18.8\%) recipients developed nonserious AEFI after the first dose of vaccination; no serious adverse event was reported among vaccine recipients. Only $2(0.3 \%)$ beneficiaries developed non-serious adverse reactions after the second dose of vaccine. Similar study from Southern India, reported a higher rate of 57\% and $14.1 \%$ for non-serious AEFI's after first dose and second dose, respectively. ${ }^{13}$ This is in line with the findings of phase 1 and phase $2 / 3$ trial of $\mathrm{ChAdOx} 1$ novel coronavirus $(\mathrm{nCoV})-19$ vaccines wherein, non-serious AEFI were reported by majority of recipients. ${ }^{14-20}$

Most of the adverse events were reported after $30 \mathrm{~min}$ but within the first $24 \mathrm{~h}$ of vaccination followed by within $30 \mathrm{~min}$ of vaccination at the centers. The rate of adverse events showed a declining trend after $24 \mathrm{~h}$ of vaccination and no adverse event was reported after 6 days

\begin{tabular}{llc}
\multicolumn{3}{l}{$\begin{array}{l}\text { Table 2: Type and frequency of AEFI with time of } \\
\text { occurrence }\end{array}$} \\
$\begin{array}{llc}\text { Time Since } \\
\text { Vaccination }\end{array}$ & $\begin{array}{l}\text { Adverse event } \\
\text { (Total AEFI = 101*) }\end{array}$ & Frequency \\
\hline Within 30 & Local reaction & \\
min & (Redness/ltching) & $2(2.0)$ \\
& Vertigo/Dizziness & $4(4.0)$ \\
Within 24 & Ghabrahat/Tachycardia & $6(5.9)$ \\
hours & Fever & $59(58.4)$ \\
& Headache & $9(8.9)$ \\
Within 7 & Local reaction & $6(5.9)$ \\
days & (Pain at injection site) & $1(1.0)$ \\
& Local reaction & \\
& (Redness/ltching) & $1(1.0)$ \\
& Nausea & $1(1.0)$ \\
& Body ache & $12(11.9)$ \\
\hline *more than one adverse event was reported by some &
\end{tabular}

\begin{tabular}{|c|c|c|c|}
\hline $\begin{array}{l}\text { Variable } \\
\text { Category }\end{array}$ & $\begin{array}{c}\text { Individuals } \\
\text { reported AEFI } \\
{[n=97]} \\
\text { (percentage of } \\
\text { category total) }\end{array}$ & $\begin{array}{c}\text { Total } \\
\text { sample } \\
(n=714)\end{array}$ & $\begin{array}{l}\text { Statistical } \\
\text { association } \\
\text { [n }=97]\end{array}$ \\
\hline \multicolumn{4}{|l|}{ Gender } \\
\hline Males & $36(12.5)$ & 287 & \multirow{3}{*}{$\begin{array}{c}0.443(1) \\
P=0.50\end{array}$} \\
\hline Females & $61(14.3)$ & 427 & \\
\hline \multicolumn{3}{|l|}{ Age group } & \\
\hline $18-39$ years & $64(12.5)$ & 514 & \multirow{3}{*}{$\begin{array}{c}3.65(2) \\
P=0.161\end{array}$} \\
\hline $40-59$ years & 33 (17.6) & 187 & \\
\hline $\begin{array}{l}\text { More than } 60 \\
\text { years }\end{array}$ & $1(7.7)$ & 13 & \\
\hline \multicolumn{4}{|l|}{ Comorbidity } \\
\hline $\begin{array}{l}\text { With } \\
\text { comorbidity }\end{array}$ & $12(17.6)$ & 68 & $\begin{array}{c}1.0561(1) \\
P=0.304\end{array}$ \\
\hline \multicolumn{4}{|l|}{ Occupation } \\
\hline Housekeeping & $31(29.5)$ & 105 & 29.71, (5), \\
\hline HCW'S & $36(11.1)$ & 324 & $P<0.001$ \\
\hline Paramedical & $8(16.0)$ & 50 & \\
\hline Medical staff. & $18(26.1)$ & 69 & \\
\hline Office staff & $6(9.8)$ & 61 & \\
\hline Students & $1(1)$ & 105 & \\
\hline
\end{tabular}

of vaccination. Other researchers also reported a similar pattern for the reported AEFIs in their study. ${ }^{21}$ About $89 \%$ of recipients did not report any adverse event after 3 days and $98.3 \%$ did not report any after 7 days of vaccination in a study abroad. ${ }^{22}$ South Indian also reported first $48 \mathrm{~h}$ to be the duration for majority of adverse events. ${ }^{13}$

In our study, overall, $18.8 \%$ of recipients reported at least one or more adverse events after the first dose. But in another studies, $57 \%{ }^{13}$ and $33.7 \%{ }^{22}$ of recipients reported adverse events after the first dose of vaccine. Much higher frequencies of adverse events (88\%) were came to light during phase $2 / 3$ trial of the $\mathrm{ChAdOx} 1 \mathrm{nCoV} 19$ vaccine..$^{23}$ Variation in the rate might be because of the variance 
Table 4: Association between time of AEFI occurrence and beneficiaries profile

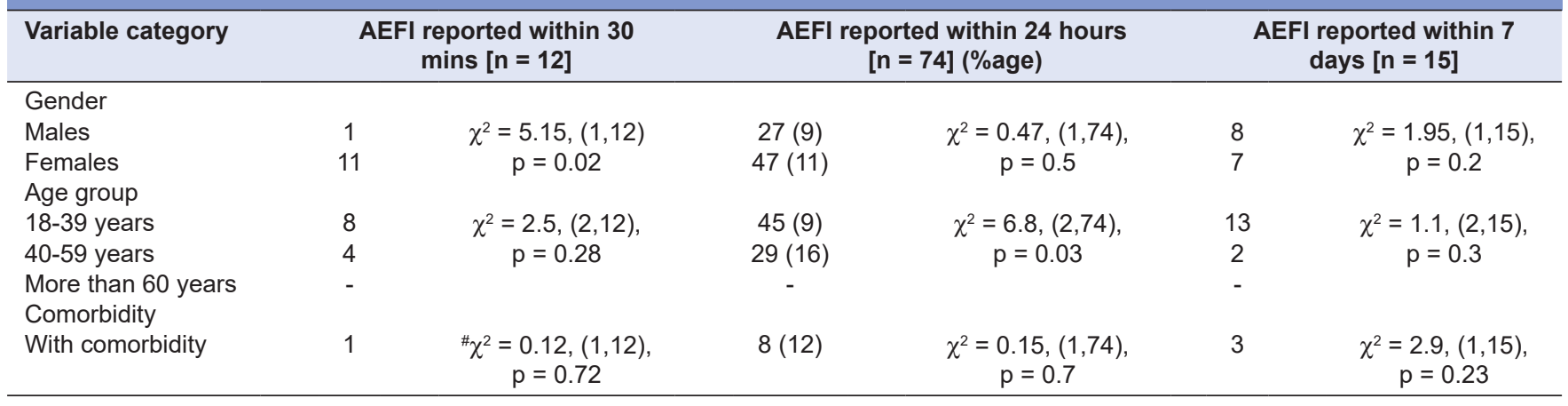

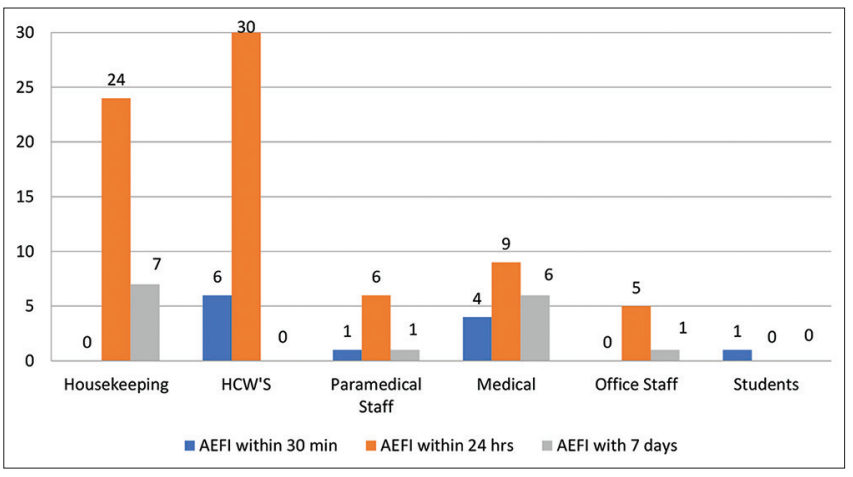

Figure 3: Distribution of adverse events following immunization (AEFI) with time and occupation of beneficiaries

in surveillance duration ${ }^{13,22}$ in different studies or ethnic variation $^{24}$ that may foretell vulnerability for AEFIs.

It was observed during the study analysis that AEFI symptoms such as pain at the injection site and fever were the most commonly reported local and systemic symptom, respectively, which is biologically explainable by the defense system physiological functioning in response to any vaccine. Our study finding, in terms of most common local and systemic reaction is well supported by other researchers. ${ }^{14,21}$ Overall, fever was reported to be the most common AEFI in this study and one conducted by Xia et $\mathrm{al}^{16}$ but injection site pain was also reported as the most frequently occurred adverse reaction in other studies. ${ }^{19,20}$ Similar study from India documented fever as third most common adverse effect after the first dose, preceded by feeling of being unwell and headache. ${ }^{13}$ No serious adverse event, such as hospitalization, disability and death, occurred during our study period which is in line with other studies as well. ${ }^{14,17,18,21-23}$ Although, serious AEFI did get reported by two patients in a study, which later found to be coincidental. ${ }^{13}$

Reporting of any AEFI (Table 3), and those reported beyond the period of first $30 \mathrm{~min}$ up to $24 \mathrm{~h}$ (Table 4), found to have a significant association with occupation. Adverse events that occurred with first 30 min showed a statistically significant association with gender and were observed more in females while middle age group of 40 59 years had significant number of adverse events between $30 \mathrm{~min}$ and $24 \mathrm{~h}$ (Table 4). These associations could be due to more awareness, concerns and/or anxiety related factors. Other studies have also reported more incidents of adverse event among females ${ }^{21,22}$ but study from India did not surface any association between gender and AEFIs following COVID-19 vaccination. ${ }^{13}$ Higher reactogenicity to the vaccine among young people compared to their older counterparts, may be the reason for more frequent symptoms, ${ }^{23}$ and that can explain the association with age, we documented in our study. However, significant association of AEFI with age $>50$ years was also reported by other researchers. ${ }^{13}$

In our study, 714 individuals were vaccinated during the first session of vaccination drive, out of which 65 persons did not report back at the respective centers for second dose vaccination. It is hypothesized that these persons must have got the vaccination from some other vaccinating center or could have delayed the vaccination due to personal reasons or in compliance to newer guidelines for Covishield regarding gap of 6-12 weeks between two vaccine doses. The incidence of AEFI was assessed among the absentee list from the second dose and was not found to have any statistically significant association. The incidence of AEFI among the second dose recipients was far lesser than the AEFI reported in the first dose. This could possible explainable based on tolerance factors or host immune response mechanisms.

\section{Limitations of the study}

The present study was done in health workers, staff, and students under the $\mathrm{CHC}$ and involves population age more than 18 years. Most of the elderly beneficiaries were not assessed for the adverse effects. In our study, comorbidity did not show any statically significant association with AEFI. As this research was planned for health workers, staff, and students, which are in working capacity hence, reflecting the mild-to-moderate comorbid status. The effect 
of AEFI alongside severe or high-grade comorbidity was not assessed in our study. The follow-up of the vaccination recipients was done till 7 days. However, AEFI associated with vaccine which may have occured after 1 week were missed out. This also relates the non-occurence of any focal neurological deficit or any symptoms related to rare adverse event like Vaccine-Induced Immune Thrombotic Thrombocytopenia, in this study. ${ }^{25}$

\section{CONCLUSION}

Most of the adverse events were short-lived and reported in the first $24 \mathrm{~h}$ of vaccination. Incidence decreased in subsequent days with no occurrence after day 6 of receiving the vaccine. No serious AEFI was reported. This study supports the fact that vaccine against COVID-19 comes with a safe and tolerable immunogenic profile in terms of adverse effects following immunization.

\section{ACKNOWLEDGMENTS}

The authors would like to thank Dr. Anoop Kumar, Senior Medical Officer, Kheri Kalan and Dr. Vandana Marya, Dental Surgeon, Kheri Kalan.

\section{REFERENCES}

1. Andrews M, Areekal B, Rajesh K, Krishnan J, Suryakala R, Krishnan B, et al. First confirmed case of COVID-19 infection in India: A case report. Indian J Med Res. 2020;151(5):490-492. https://doi.org/10.4103/ijmr.IJMR_2131_20

2. World's $1^{\text {st }}$ Covid-19 Vaccine Approved! UK First Country to Give Nod to Pfizer and BioNTech Candidate. Available from: https:// www.businesstoday.in/coronavirus/breaking-uk-becomesfirst-country-to-approve-pfizerbiontech-vaccine-for-mass-use/ story/423636.html [Last accessed on 2021 Jan 28].

3. Coronavirus Vaccine News Highlights: Fever, Headache, Nausea Most-reported Adverse Effects Post Vaccination, Says Health Ministry Deccan Herald. Available from: https://www. deccanherald.com/national/coronavirus-vaccine-live-newsupdates-astrazeneca-oxford-bharat-biotech-covaxin-covishieldhealthworkers-free-vaccine-vaccination-drive-India-seruminstitute-jan-16-narendra-modi-939958.html\#1 [Last accessed on 2021 Jan 28].

4. World Health Organization. Adverse Events Following Immunization (AEFI). Available from: https://www.who.int/ vaccine_safety/initiative/detection/AEFI/en [Last accessed on 2021 Jan 27].

5. Coronavirus Disease (COVID-19): Vaccines. Available from: https://www.who.int/news-room/q-a-detail/coronavirusdisease-(covid-19)-vaccines?adgroupsurvey=\%7Badgroups urvey\%7D\&gclid=CjwKCAiAu8SABhAxEiwAsodSZCfyN806 YC1dVuDMkKM-vff8mPg0geptXSqBMAEJN1X7Vcyqnmalho $\bar{C}$ REgQAvD_BwE [Last accessed on 2021 Jan 28].

6. COVID-19: Risks and Side Effects of Vaccination Science indepth Reporting on Science and Technology; 2021. Available from: https://www.dw.com/en/covid-19-risks-and-side-effects-ofvaccination/a-56136620 [Last accessed on 2021 Jan 27].
7. No Serious Adverse Effect Reported Yet: Govt. on COVID Vaccination. Available from: https://www.thequint.com/ coronavirus/no-covid-vaccine-adverse-effects-concerns-so-farhealth-ministry\#read-more [Last accessed on 2021 Jan 28].

8. COVID-19 Vaccination: 447 Recipients across India Suffer Adverse Events Post Inoculation; how AEFI is Tracked, Reported Health News, Firstpost. https://www.firstpost.com/ health/covid-19-vaccination-447-recipients-across-indiasuffer-adverse-events-post-inoculation-how-aefi-is-trackedreported-9210391.html [Last accessed on 2021 Jan 27].

9. Covid Vaccines Safe, Only $0.18 \%$ Adverse Events so far: Government India News Times of India. Available from: https:// timesofindia.indiatimes.com/india/covid-vaccines-safe-only-018-adverse-events-so-far-government/articleshow/80349058. cms [Last accessed on 2021 Jan 27].

10. Two Persons Exhibit Adverse Events after Receiving COVID-19 Vaccine in Odisha. Available from: https://www.aninews.in/news/ national/general-news/two-persons-exhibit-adverse-eventsafter-receiving-covid-19-vaccine-in-odisha20210122031650 [Last accessed on 2021 Jan 28].

11. Moderna Vaccine Adverse Effects Reported United States Coronavirus Vaccine World News India TV. Available from: https:// www.indiatvnews.com/news/world/moderna-vaccine-adverseeffects-reported-united-states-coronavirus-vaccine-679899 [Last accessed on 2021 Jan 27].

12. COVID-19 Vaccine Safety: Weekly Report on Adverse Effects Following Immunization. Available from: https://healthinfobase.canada.ca/covid-19/vaccine-safety [Last accessed on 2021 Jan 28].

13. Kamal D, Thakur V, Nath N, Malhotra T, Gupta A and Batlish R. Adverse events following ChAdOx1 nCoV-19 Vaccine (COVISHIELD) amongst health care workers: A prospective observational study. Med J Armed Forces India. 2021;77(Suppl 2):S283-S288. https://doi.org/10.1016/J. MJAFI.2021.06.014

14. Zhu FC, Li YH, Guan XH, Hou LH, Wang WJ, Li JX, et al. Safety, tolerability, and immunogenicity of a recombinant adenovirus type-5 vectored COVID-19 vaccine: A dose-escalation, open-label, non-randomised, first-in-human trial. Lancet. 2020;395(10240):1845-1854.

https://doi.org/10.1016/S0140-6736(20)31208-3

15. Zhu FC, Guan XH, Li YH, Huang JY, Jiang T, Hou LH, et al. Immunogenicity and safety of a recombinant adenovirus type-5vectored COVID-19 vaccine in healthy adults aged 18 years or older: A randomised, double-blind, placebo-controlled, phase 2 trial. Lancet. 2020;396(10249):479-488.

https://doi.org/10.1016/S0140-6736(20)31605-6

16. Xia S, Zhang Y, Wang Y, Wang H, Yang YK, Gao GF, et al. Safety and immunogenicity of an inactivated SARS-CoV-2 vaccine, BBIBP-CorV: A randomised, double-blind, placebo-controlled, phase 1/2 trial. Lancet Infect Dis. 2021;21(1):39-51. https://doi.org/10.1016/S1473-3099(20)30831-8

17. Xia S, Duan K, Zhang Y, Zhao D, Zhang H, Xie Z, et al. Effect of an inactivated vaccine against SARS-CoV-2 on safety and immunogenicity outcomes: Interim analysis of 2 randomized clinical trials. JAMA. 2020;324(10):951-960. https://doi.org/10.1001/jama.2020.15543

18. Folegatti PM, Ewer KJ, Aley PK, Angus B, Becker S, BelijRammerstorfer $S$, et al. Safety and immunogenicity of the ChAdOx1 $\mathrm{nCoV}-19$ vaccine against SARS-CoV-2: A preliminary report of a phase 1/2, single-blind, randomised controlled trial. Lancet. 2020;396(10249):467-478. https://doi.org/10.1016/S0140-6736(20)31604-4

19. Ella R, Vadrevu KM, Jogdand H, Prasad S, Reddy S, Sarangi V, et al. Safety and immunogenicity of an inactivated SARS-CoV-2 
vaccine, BBV152: A double-blind, randomised, phase 1 trial. Lancet Infect Dis. 2021;21(5):637-646.

https://doi.org/10.1016/S1473-3099(20)30942-7

20. Logunov DY, Dolzhikova IV, Zubkova OV, Tukhvatullin AI, Shcheblyakov DV, Dzharullaeva AS, et al. Safety and immunogenicity of an rAd26 and rAd5 vector-based heterologous prime-boost COVID-19 vaccine in two formulations: Two open, non-randomised phase 1/2 studies from Russia. Lancet (London, England). 2020;396(10255):887-897.

https://doi.org/10.1016/S0140-6736(20)31866-3

21. Tequare MH, Abraha HE, Adhana MT, Tekle TH, Belayneh EK, Gebresilassie KB, et al. Adverse events of Oxford/AstraZeneca's COVID-19 vaccine among health workers of ayder comprehensive specialized hospital, Tigray, Ethiopia. IJID Reg. 2021;1:124-129. https://doi.org/10.1016/J.IJREGI.2021.10.013

22. Menni C, Klaser K, May A, Polidori L, Capdevila J, Louca P, et al. Vaccine side-effects and SARS-CoV-2 infection after vaccination in users of the COVID symptom study app in the
UK: A prospective observational study. Lancet Infect Dis. 2021;21(7):939-949

https://doi.org/10.1016/S1473-3099(21)00224-3

23. Ramasamy MN, Minassian AM, Ewer KJ, Flaxman AL, Folegatti PM, Owens DR, et al. Safety and immunogenicity of ChAdOx1 nCoV-19 vaccine administered in a prime-boost regimen in young and old adults (COV002): A single-blind, randomised, controlled, phase $2 / 3$ trial. Lancet (London, England). 2020;396(10267):1979.

https://doi.org/10.1016/S0140-6736(20)32466-1

24. Baehr A, Peña JC and Hu DJ. Racial and ethnic disparities in adverse drug events: A systematic review of the literature. J Racial Ethn Health Disparities. 2015;2(4):527-536. https://doi.org/10.1007/S40615-015-0101-3/TABLES/2

25. Pai M, Chan B, Stall NM, Grill A, Ivers N, Maltsev A, et al. Vaccineinduced immune thrombotic thrombocytopenia (VITT) following adenovirus vector COVID-19 vaccination. Sci Briefs. 2021;2:1-9. https://doi.org/10.47326/ocsat.2021.02.17.2.0

\section{Authors' Contributions:}

CC-Concept and design of the study, data collection, reviewed the literature; MS- Statistical analysis, manuscript writing; MNAK- Statistical analysis and interpretation, preparation of manuscript; BKA- Preparation of manuscript; SS- Preparation of manuscript

\section{Work attributed to:}

Al-Falah School of Medical Sciences and Research Centre, Dhauj, Faridabad, Haryana, India

\section{ORCID ID:}

Dr. Chintu Chaudhary - https://orcid.org/0000-0003-4196-8651

Mukhmohit Singh - (i) https://orcid.org/0000-0001-6642-5384

Dr. Mohd. Najmul Aqib Khan - (1) https://orcid.org/0000-0001-6575-5023

Bhupinder Kaur Anand - (iD https://orcid.org/0000-0003-2454-3547

Shveta Saini - io https://orcid.org/0000-0001-8636-6019

Source of Funding: None, Conflicts of Interest: None. 